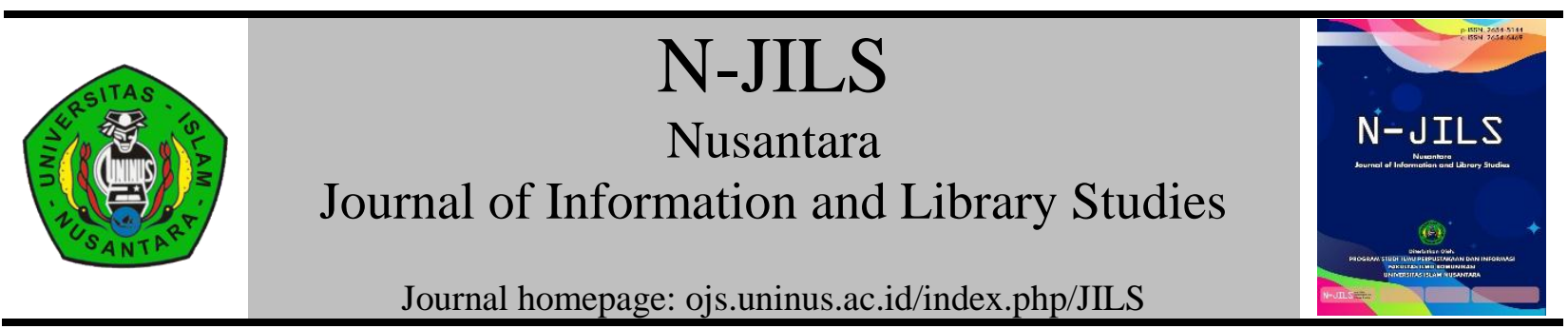

\title{
Pengelolaan Arsip Inaktif Internal Di Dinas Perpustakaan Dan Kearsipan Daerah Kabupaten Banyuasin
}

\section{Management Of Internal Inactive Records In The Banyuasin District Library And Archives Service}

\author{
Intan Kesuma Fitri ${ }^{1}$, Rusmiatiningsih ${ }^{2}$ \\ ${ }^{1}$ Program Studi Ilmu Perpustakaan, UIN Raden Fatah Palembang. \\ ${ }^{2}$ Program Studi Ilmu Perpustakaan, UIN Raden Fatah Palembang. \\ Email: ${ }^{* 1}$ Intanfitri26@gmail.com, ${ }^{2}$ Rusmiatiningsih38@ yahoo.com
}

\begin{tabular}{ll}
\hline ARTICLE INFO & ABSTRACT \\
\hline Article history & This study discusses the Management of Internal \\
Received [June,2020] & Inactive Records in the Banyuasin District Library \\
Accepted [June,2020] & and Archives Service. This study aims to determine \\
Available Online [June,2020] & how the management of internal inactive records in \\
the Banyuasin District Library and Archives Service, \\
as well as any obstacles encountered in managing the \\
internal inactive records and their coping efforts at \\
the Banyuasin District Library and Archives Service. \\
This research uses a qualitative descriptive research \\
type. The data collection methods in this research are \\
in the form of observations, interviews, and \\
documentation. Information in this research is, one \\
Head of Archive Management Division, one Head of \\
Dynamic Records Management Section and one \\
Manager of Household Infrastructure and Services. \\
The results of this study indicate that the process of \\
managing internal inactive records in the Banyuasin \\
District Library and Archives Service has \\
implemented a life cycle or record life cycle manually. \\
In addition, it has also implemented semi-automation, \\
namely by applying the transfer of archive media. The \\
constraints faced in managing the internal inactive \\
.
\end{tabular}


records are Human Resources / Archivists who are lacking, have not carried out annihilation, and have not re-used the automation system.

Keywords: record management, inactive records.

Kata kunci:pengelolaan arsip, arsip inaktif

\begin{abstract}
ABSTRAK
Penelitian ini membahas mengenai Pengelolaan Arsip Inaktif Internal di Dinas Perpustakaan dan Kearsipan Daerah Kabupaten Banyuasin. Penelitian ini bertujuan untuk mengetahui bagaimana pengelolaan arsip inaktif internal di Dinas Perpustakaan dan Kearsipan Daerah Kabupaten Banyuasin, serta kendala-kendala apa saja yang dihadapi dalam pengelolaan arsip inaktif internal dan upaya penanggulangannya di Dinas Perpustakaan dan Kearsipan Daerah Kabupaten Banyuasin. Penelitianinimenggunakanjenispenelitian deskriptif kualitatif. Metodepengumpulandata padapenelitianini yaitu berupa, observasi, wawancara, dandokumentasi.Informan di dalampenelitianiniyaitu, satu Kepala Bidang Pengelolaan Arsip, satu Kepala Seksi Pengelolaan Arsip Dinamis Dan satu Pengelola Sarana Dan Prasarana Rumah Tangga Dinas. Hasil penelitian ini menunjukan bahwa proses pengelolaan arsip inaktif internal di Dinas Perpustakaan dan Kearsipan Daerah Kabupaten Banyuasin telah menerapkan life cycle atau siklus hidup rekod secara manual. Selain itu juga sudah menerapkan semi otomasi, yaitu dengan menerapkan alih media arsip. Adapun kendala-kendala yang dihadapi dalam pengelolaan arsip inaktif internal yaitu Sumber Daya Manusia/Arsiparis yang kurang, belum melakukan pemusnahan, dan belum menggunakan kembali sistem otomasi.
\end{abstract}

(C) 2020 NJILS. All rights reserved.

\title{
A. PENDAHULUAN
}

Dewasa ini kebutuhan primer masyarakat tidak terbatas yaitu sandang, pangan, papan melainkan juga informasi. Informasi dianggap penting karena peranannya sangat besar bagi kehidupan dalam berbagai bidang seperti politik, ekonomi, sosial budaya dan lain sebagainya. Informasi adalah data yang sudah diolah menjadi sebuah bentuk yang berarti bagi pengguna, yang bermanfaat dalam pengambilan keputusan saat ini atau mendukung sumber informasi(Kusrini, 2007). Salah satu sumber informasi yaitu arsip. 
Arsip adalah informasi terekam, apapun media atau karakteristiknya, yang dibuat atau diterima oleh suatu organisasi yang berguna dalam kegiatan suatu organisasi (Krihanta, 2014). Arsip juga harus dikelola dengan baik oleh suatu unit atau lembaga kearsipan. Salah satu lembaga kearsipan di Sumatera Selatan adalah Dinas Perpustakaan dan Kearsipan Daerah Kabupaten Banyuasin.

Lembaga kearsipan adalah sebuah organisasi yang mempunyai kegiatan. Kegiatannya yaitu selain mengelola arsip dari luar atau dari OPD lain juga mengelola arsipnya sendiri. Arsip yang mereka kelola sendiri disebut dengan arsip internal. Arsip internal tersebut dikelola oleh unit kerja kemudian unit kearsipan. Arsip internal yang dikelola di Dinas Perpustakaan dan Kearsipan Daerah Kabupaten Banyuasin adalah arsip aktif internal dan arsip inaktif Internal. Akan tetapi yang akan di bahas dalam skripsi ini adalah arsip inaktif internal.

Arsip inaktif internal tersebut perlu dilakukan pengelolaan arsip dengan baik, agar mudah ditemukan kembali. Sebagai lembaga kearsipan yang mengelola arsip dari OPD lain, seharusnya Dinas Perpustakaan dan Kearsipan Daerah Kabupaten Banyuasin harus mengelola arsip inaktif internalnya dengan baik. Misalnya : arsip dari sekretariat maupun arsip perbidang.

Namun pengelolaan arsip inaktif internal tersebut sering menjumpai permasalahanpermasalahan, sehingga menyebabkan pengelolaan arsip inaktif internal tersebut tidak optimal dan menghambat pengelolaan arsip inaktif internal. Demikian juga yang dialami Dinas Perpustakaan dan Kearsipan Daerah Kabupaten Banyuasin. Berdasarkan hasil observasi yang dilakukan peneliti, ditemukan permasalahan yang dihadapi oleh Dinas Perpustakaan dan Kearsipan Daerah Kabupaten Banyuasin adalah SDM atau arsiparis, pemeliharaan/pelestarian arsip, pemusnahan, otomasi arsip.

Penelitian ini menunjukan bahwa pengelolaan arsip inaktif di Dinas Perpustakaan dan Kearsipan Daerah Kabupaten Banyuasin sudah baik. Akan tetapi terdapat tahap-tahap pengelolaan arsip inaktif yang belum dilakukan yaitu pemusnahan arsip. Juga, kendalakendala yang dihadapi dalam pengelolaan arsip inaktif yaitu SDM atau arsiparis yang sangat kurang mengakibatkan sulitnya mengelola arsip dengan baik, terjadinya penumpukan arsip inaktif sehingga pengelola arsip atau arsiparis sulit menemukan kembali arsip inaktif dan belum menggunakan kembali otomasi arsip berbasis aplikasi. Adapun tujuan yang ingin 
dicapai adalah mengetahui pengelolaan arsip inaktif internal serta kendala dan upaya penanggualangannya.

\section{B. TINJAUAN PUSTAKA}

Berkaitan dengan penelitian ini, sebelumnya telah ada peneliti-peneliti lain yang melakukan penelitian di bidang arsip inaktif diantaranya yang ditulis oleh Rulli Susfa Ramanda dan Sri Indrahti dalam Jurnal yang berjudul "Analisis Pengelolaan Arsip Inaktif Terhadap Temu Kembali Arsip Di Pusat Arsip (Record Center) Politeknik Negeri Semarang". Tujuan penelitian ini adalah untuk mengetahui pengelolaan arsip, proses temu kembali arsip dan pengaruh pengelolaan arsip inaktif terhadap temu kembali arsip di Pusat Arsip (Record Centre) Politeknik Negeri Semarang (Rulli dan Sri, 2015).

Penelitian kedua, Oleh Nita Rahmawati dan Ismiyati dalam Jurnalnya yang berjudul "Pengelolaan Arsip Inaktif Dalam Upaya Mendukung Layanan Informasi Di Kantor Arsip Dan Perpustakaan Daerah Kabupaten Purworejo". Penelitian ini menggunakan penelitian kualitatif. Sumber data dalam penelitian ini adalah Kepala Kantor Arsip dan Perpustakaan Daerah Kabupaten Purworejo, Kepala Bagian Tata Usaha, Kepala Seksi Akuisisi, Pengelolaan Arsip dan Dokumentasi, Staff Sub Tata Usaha, dan Arsiparis. Teknik pengumpulan data dalam penelitian ini menggunakan observasi, wawancara dan dokumentasi (Nita dan Ismiyati, 2016).

Penelitian ketiga, Oleh Rendra Muslim dalam skripsinya yang berjudul "Pengelolaan Arsip Inaktif Di Dinas Pengelolaan Keuangan Dan Aset Daerah Kabupaten Sleman”. Penelitian ini bertujuan untuk mengetahui pengelolaan arsip inaktif di Dinas Pengelolaan Keuangan dan Aset Daerah Kabupaten Sleman terutama yang berkaitan dengan; 1) Pengelolaan arsip inaktif; 2) Kendala yang dihadapi dalam pengelolaan arsip inaktif; 3) Usaha dalam mengatasi kendala yang dihadapi dalam pengelolaan arsip inaktif (Rendra, 2014).

Arsip menurut ICA (International Council on Archives) arsip adalah infromasi terekam yang dibuat atau diterima dalam rangka perencanaan, pengendalian pelaksanaan atau penyelesaian kegiatan kelembagaan atau penyelesaian kegiatan kelembagaan atau perseorangan dan terdiri atas isi, konteks, dan struktur yang memadai untuk bisa menjadi bukti dari suatu kegiatan (Sumrahyadi, 2014). Pengelolaan arsip adalah kegiatan menerima, menyimpan, mengaktulisasikan dan menemukan kembali arsip inaktif yang disimpan 
berdasarkan pada prinsip efektivitas, efesiensi dan keamanan yang didukung oleh sumber daya manusia yang berkualitas, lembaga yang mantap dan sarana prasarana yang memadai (Rulli, 2015). Tujuan Pengelolaan arsip inaktif menurut Betty Ricks adalah sebagai berikut, yaitu mengurangi jumlah total arsip yang diselenggarakan di area penyimpanan dan kantor sehingga akan dapat mengurangi biaya penyimpanan arsip organisasi; melakukan pengendalian untuk menjamin pemindahan arsip secara terus-menerus dari kantor ke tempat penyimpanan; membebaskan ruang dan mengurangi kebutuhan perlengkapan, serta mengurangi biaya penyimpanan arsip; membuat sistem penemuan kembali yang efisien, memberikan akses terhadap arsip yang sewaktu-waktu diperlukan untuk pengambilan keputusan; mengembangkan program microfilm yang didukung biaya (jika perlu), dan menjaga keamanan penuh tentang arsip perusahaan (Sujono, 2014).

Teori pengelolaan arsip inaktif yang digunakan oleh peneliti adalah kedua siklus hidup rekod dari Hani Qonitah dan Patricia Wallace dan satu pengelolaan arsip menurut undang-undang nomor 43 tahun 2009 sehingga siklus hidup rekod yang digunakan dari ketiganya menjadi 8 siklus hidup rekod yang terdiri dari penciptaan, distribusi, penggunaan dan pemeliharaan, penyimpanan rekod aktif, pemindahan, penyimpanan rekod inaktif, pemusnahan, dan penyimpanan permanen. Dari teori life cycle yang sudah ditampilkan sebelumnya, maka bisa direpresentasi life cycle menjadi beberapa 8 tahapan yaitu, pertama, penciptaan arsip adalah proses menciptakan arsip melalui kegiatan perekam informasi dalam rangka melaksanakan tugas dan fungsi dari organisasi (Sovia, 2017). Penciptaan rekod adalah kegiatan membuat dan/atau menerima rekod oleh seorang karyawan atau unit kerja dalam satu organisasi (Hani, 2013). Kedua, pendistribusian arsip adalah penyampaian arsip atau pengendalian pergerakan arsip dari satu unit kerja ke unit kerja lain (Universitas Negeri Semarang, 2013). Ketiga, penggunaan dan Pemeliharaan. Pemeliharaan, merupakan usaha pengamanan arsip agar terawat dengan baik, sehingga mencegah kemungkinan adanya kerusakan dan kehilangan arsip. Pemeliharaan dan perawatan arsip untuk melestarikan kandungan informasi arsip dengan alih bentuk menggunakan media lain atau melestarikan bentuk aslinya dapat digunakan secara optimal, karena arsip merupakan suatu temuan informasi yang dapat mempertahankan hak milik seseorang, instan maupun Negara (Aldona dan Elva, 2013). Pemeliharaan arsip inaktif adalah proses atau cara menjaga, melindungi dan menyelamatkan arsip inaktif (Sujono, 2014). Keempat, Penyimpanan rekod aktif adalah arsip yang masih sering digunakan dalam berbagai kegiatan perusahaan kemudian di simpan di tempat penyimpanan dengan status aktif (Ida, 2014). Kelima, pemindahan arsip inaktif 
merupakan kegiatan tahap awal dalam siklus pengelolaan arsip inaktif setelah fasilitas penyimpanan tersedia dalam suatu instansi (Sujono, 2014). Keenam, penyimpanan rekod inaktif adalah arsip diterima dari unit kerja dalam rangka pemindahan arsip inaktif, diberikan kode lokasi sesuai sistem nomor yang digunakan sampai pada penataan dan penyimpanan boks arsip dalam rak arsip di ruang penyimpanan. Ketujuh, pemusnahan adalah kegiatan penghancurkan secara total dokumen perusahaan yang telah habis fungsinya dan yang tidak lagi memiliki nilai guna. Kedelapan, penyimpanan permanen bisa disebut juga dengan arsip statis.Arsip Arsip statis berasal dari arsip dinamis yang mempunyai nilai keberanjuran (continuingvalue), kemudian disimpan permanen karena informasinya mengandung nilai historis (historcal value) (Krihanta, 2014).

\section{METODE PENELITIAN}

Metode Penelitian adalah sekumpulan peraturan, kegiatan dan prosedur secara teknis atau metode-metode yang digunakan oleh peneliti dalam penelitiannya (Tim Peyusun, 2013). Penelitian ini menggunakan metode penelitian deskriptif kualitatif. Penelitian kualitatif merupakan metode-metode untuk mengeksplorasi dan memahami makna yang dianggap berasal dari masalah sosial atau kemanusiaan(Helen, 2015). Objek dari penelitian ini adalah pengelolaan arsip inaktif internal, sedangkan subjek dari penelitian ini adalah pegawai kearsipan.

Adapun Informan adalah orang yang memberi informasi atau orang yang menjadi sumber data dalam penelitian (narasumber) (Penyusun Kamus Pusat Pembinaan, 2013). Informan yang akan diwawancarai adalah Kepala Bidang Pengelolaan Arsip, Kepala Seksi Pengelolaan Arsip Dinamis, dan Pengelola Sarana dan Prasarana Rumah Tangga yang bekerja di Dinas Perpustakaan dan Kearsipan Daerah Kabupaten Banyuasin. Penentuan informan yang digunakan ditentukan dengan menggunakan teknik purposive sampling. Menurut Prijana, purposive atau judgemental sampling adalah dasarnya terletak kepada keputusan peneliti dan tujuan studi, maka dalam sampling purposive ketepatan estimasi ditentukan oleh kreativitas peneliti dalam menerjemahkan populasi. (Helen, 2015). Jadi informan yang cocok untuk digunakan dalam penelitian ini yaitu satu orang Kepala Bidang Pengelolaan Arsip, satu orang Kepala Seksi Pengelolaan Arsip Dinamis, dan satu orang Pengelola Sarana dan Prasarana Rumah Tangga. Jadi total informan yang akan peneliti gunakan adalah tiga orang.

Jenis Data yang digunakan dalam penelitian ini yaitu data kualitatif. Data kualitatif berupa informasi dan hasil wawancara kepada arsiparis atau pengelola arsip untuk 
mengetahui pengelolaan arsip inaktif yang telah dilakukan oleh Dinas Perpustakaan dan Kearsipan Daerah Kabupaten Banyuasin. Adapun sumber Data yng digunakan adalah sumber primer, dan sekunder. Sumber primer adalah yang langsung diperoleh dari sumber data pertama di lokasi penelitian atau objek penelitian (Burhan, 2017). Jadi, sumber data primer adalah data yang diperoleh langsung dari objek penelitian tersebut dari hasil wawancara antara peneliti dan narasumber. Sumber data sekunder adalah data yang diperoleh dari sumber kedua atau sumber sekunder dari data yang kita butuhkan (Burhan, 2017).

Teknik Pengumpulan Data adalah observasi, wawancara dan dokumentasi. Observasi adalah suatu penelitian secara sistematis menggunakan kemampuan indra manusia (Endraswara, 2016).Observasi digunakan untuk memperoleh data mengenai pengolaan arsip inaktif internal, yaitu dengan cara mengamati secara langsung tentang objek penelitian yang berhubungan dengan Dinas Perpustakaan dan Kearsipan Daerah Kabupaten Banyuasin, kemudian data observasi tersebut dipadukan dengan data yang diperoleh dari hasil wawancara. Adapun wawancara yang peneliti lakukan adalah wawancara mendalam (indepth interview) adalah seperti survei, metode yang memungkinkan pewawancara untuk bertanya kepada responden dengan harapan untuk memperoleh informasi mengenai fenomena yang ingin di teliti (West dan Lynn, 2008). Dokumentasi merupakan teknik pengumpulan data penelitan mengenai hal-hal atau variabel yang berupa catatan, transkip, buku, surat, koran, majalah, prasasti, notulen rapat, leger nilai, agenda, dan lain-lain (Johni, 2013).

Teknik Analisis Data yang digunakan adalah reduksi data, penyajian data, dan Verifikasi dan Penarikan Kesimpulan (Fitrah, 2017). Reduksi adalah data yang diperoleh peneliti dari hasil observasi di lapangan, wawancara dan dokumentasi. Penyajian Data dimaksudkan untuk menemukan pola-pola yang bermakna serta memberikan kemungkinan adanya penarikan simpulan serta memberikan tindakan (Johni, 2013). Verifikasi adalah suatu tinjauan ulang pada pengamatan di lapangan dan hasil wawancara atau peninjauan kembali data yang ada, data dapat dilihat dari laporan arsip, dari data tersebut harus diuji kebenarannya, kecocokannya yang merupakan validitas setelah itu baru ditarik suatu kesimpulan.

\section{HASIL DAN PEMBAHASAN}

Pengelolaan Arsip Inaktif Internal di Dinas Perpustakaan Dan Kearsipan Daerah Kabupaten Banyuasin, yaitu, pertama, penciptaan. Penciptaan merupakan kegiatan 
menciptakan atau membuat arsip di dalam lingkup unit kerja kearsipan, maksudnya disini adalah surat menyurat, dokumen-dokumen, data keuangan, dan lain-lain yang dihasilkan dari lingkup unit kerja kearsipan. Kedua, Pemindahan adalah kegiatan memindahkan arsip aktif ke arsip inaktif yang disimpan dalam jangka waktu tertentu tergantung nilai guna arsip aktif tersebut. Pemindahan dilakukan dengan cara dipilah dan didata terlebih dahulu, setelah itu di buat berita acara pemindahan arsip inaktif dan dilampiri daftar arsip inaktif. Ketiga, Pemeliharaan adalah kegiatan memelihara arsip inaktif dengan cara melakukan penataan, penyimpanan, alih media, dan perlindungan, meliputi penataan, penyimpanan, alih media dan perlindungan. Keempat, penggunaan adalah kegiatan menggunakan kembali atau kegiatan peminjaman arsip inaktif yang telah disimpan, akan tetapi yang boleh meminjam atau menggunakan kembali arsip inaktif internal adalah orang-orang tertentu seperti kepala bidang atau kepala seksi pengelolaan arsip.

Adapun Kendala Pengelolaan Arsip Inaktif Internal di Dinas Perpustakaan dan Kearsipan daerah Kabupaten Banyuasin, yaitu, pertama, kurangnya Sumber Daya Manusia atau Arsiparis. Perpustakaan dan Kearsipan Daerah Kabupaten Banyuasin masih sangat kurang tenaga kerja arsiparis, arsiparis yang ada hanya satu orang. Selain itu Sumber Daya Manusia (SDM) yang telah di bina dalam pengelolaan arsip banyak yang dipindahkan ke dinas lain, sehingga bisa menghambat pengelolaan arsip. Akibatnya Dinas Perpustakaan dan Kearsipan Daerah Kabupaten Banyuasin harus memulai kembali untuk mencari Sumber Daya Manusia atau Arsiparis yang akan dibina kembali. Kedua, penumpukan arsip. Arsip inaktif yang berada di Dinas Perpustakaan dan Kearsipan Daerah Kabupaten Banyuasin sangat banyak karena belum melakukan pemusnahan sampai sekarang ini, akibatnya pegawai kearsipan atau arsiparis sulit untuk menemukan kembali arsip yang telah disimpan tersebut. Ketiga, otomasi Arsip (Aplikasi). Dinas Perpustakaan dan Kearsipan Daerah Kabupaten Banyuasin tersebut belum menggunakan kembali otomasi arsip berbasis aplikasi sebab Dinas Kominfo Banyuasin belum menyediakan kembali jaringan LAN yang telah rusak untuk menunjang aplikasi otomasi arsip seperti SIKD, SIMARDI, SIPAS dan lain-lain.Tanpa jaringan LAN aplikasi tersebut tidak bisa terhubung dari komputer satu ke komputer lainnya.Dinas Perpustakaan dan Kearsipan Daerah Kabupaten Banyuasin juga tidak bisa menggunakan jaringan LAN di lingkup kerjanya sendiri disebabkan anggaran untuk menggunakan jaringan LAN terlalu besar.

Upaya Penanggulannya di Dinas Perpustakaan dan Kearsipan daerah Kabupaten Banyuasin, yaitu, pertama, kurangnya Sumber Daya Manusia atau Arsiparis. Upaya 
penanggulangan SDM atau arsiparis yang kurang adalah SDM atau pengelola arsip diikutkan sertakan bimtek atau pelatihan kearsipan dan untuk arsiparis sudah mengusulkan ke BKD untuk memasukkan jabatan fungsional arsiparis dalam penerimaan CPNS yang akan datang sedangakan untuk jangka pendeknya, mengusulkan ke BKD untuk menarik PNS yang sudah mengikuti Diklat Pengangkatan Arsiparis Tingkat Terampil. Kedua, penumpukan arsip. Upaya penanggulangan penumpukan arsip adalah dilakukan pengolahan arsip inaktif secara berkala dan penunjukkan pengelola arsip yang bertugas mengelola arsip inaktif. Ketiga, otomasi Arsip (Aplikasi). Upaya penanggulangan otomasi arsip yang belum digunakan kembali adalah Dinas Perpustakaan dan Kearsipan Daerah Kabupaten Banyuasin menggunakan otomasi arsip manual seperti microsoft excel untuk menyimpan daftar arsip inaktif dan menggunakan scanner untuk alih media kertas dari manual ke digital.

\section{E. KESIMPULAN DAN SARAN}

Pengolahan arsip inaktif internal di Dinas Perpustakaan dan Kearsipan Daerah Kabupaten Banyuasin sudah berjalan sesuai dengan tahapan life cycle/siklus hidup rekod secara manual yaitu pada tahapan penciptaan, pemindahan, penataan, penyimpanan, perlindungan dan pengggunaan. Akan tetapi, pengelolaan arsip inaktif tersebut tidak sepenuhnya melakukan tahapan-tahapan life cycle secara manual, karena pengelolaan arsip inaktif internal yang dilakukan oleh Dinas Perpustakaan dan Kearsipan Daerah Kabupaten Banyuasin sudah melakukan semi otomasi. Pengelolaan arsip inaktif internal semi otomasi tersebut terdapat pada tahapan alih media arsip. Secara keseluruhan pengelolaan arsip inaktif internal ini cukup optimal, karena masih ada tahapan-tahapan yang belum dilakukan oleh Dinas Perpustakaan dan Kearsipan Daerah Kabupaten Banyuasin.Kendala yang dihadapi oleh Dinas Perpustakaan dan Kearsipan Daerah Kabupaten Banyuasin dalam menghadapi pengelolaan arsip inaktif adalah SDM atau arsiparis yang kurang mengakibatkan sulitnya mengelola arsip dengan baik, kedua terjadinya penumpukan arsip inaktif sehingga pengelola arsip atau arsiparis sulit menemukan kembali arsip inaktif dan ketiga belum menggunakan kembali otomasi arsip berbasis aplikasi.

Adapun saran berdasarkan pada kesimpulan yang diperoleh sebaiknya pemusnahan arsip inaktif segera dilaksanakan sebab bisa terjadinya penumpukan arsip inaktif yang terlalu banyak dan mengakibatkan arsip berhamburan dan sulit untuk ditemukan kembali kemudian sebaiknya Sumber Daya Manusia atau arsiparis ditambahkan lagi agar pengelolaan arsip terkelola dengan baik, kemudian sebaikya Dinas Perpustakaan dan Kearsipan Daerah 
Kabupaten Banyuasin menyediakan kembali arsip berbasis otomasi agar memudahkan lembaga arsip ini mengelola arsip dengan cepat serta dalam temu kembali arsip, lalu sebaiknya pemeliharaan arsip dibagian pembersihan arsip setiap 2-3 bulan sekali tidak menggunakan kemoceng, tetapi menggunakan vacum cleaner agar lebih optimal sehingga debu-debu tidak mengenai box lain. Selain itu, sebaiknya Dinas Perpustakaan dan Kearsipan Daerah Kabupaten Banyuasin melakukan pembersihan arsip secara rutin atau minimal satu bulan sekali agar debu tidak menumpuk terlalu banyak, dan sebaiknya menggunakan undangundang arsip terbaru yang telah diperbaharui dari pada yang lama, sebab kata-kata arsip dinamis tidak digunakan lagi oleh versi undang-undang yang terbaru.

\section{DAFTAR PUSTAKA}

Bungin, Burhan. (2017). Metodologi Penelitian Kuantitatif: Komunikasi, Ekonomi, dan Kebijakan Publik Serta Ilmu-Ilmu Sosial Lainnya, Jakarta: Kencana.

Dimyati, Johni. (2013). Metodologi Penelitian Pendidikan Dan Aplikasinya Pada Pendidikan Anak Usia Dini $(P A U D)$. Jakarta: Kencana.

Endraswara, Suwardi. (2006). Metode, Teori, Teknik Peneitian Kebudayaan: Ideologi, Epistemologi dan Aplikasi. Yogyakarta : Pustaka Widyatama.

Fitrah, Muh. dan Luthfiyah. (2017). Metodologi Penelitian: Penelitian Kualitatif, Tindakan Kelas dan Studi Kasus, Jawa Barat: CV Jejak.

Gusda, Aldona dan Elva Rahmah. (2013). Pemeliharaan Dan Perawatan Arsip Statis Di Kantor Arsip Kabupaten Pesisir Selatan. Jurnal Ilmu Informasi Perpustakaan dan Kearsipa,2(1). DOI : https://doi.org/10.24036/2441-0934

Krihanta. (2014). Pengelolaan Arsip Vital. Tanggerang Selatan: Universitas Terbuka.

Kusrini. (2007). Tuntunan Praktis Membangun Sistem Informasi Akuntansi dengan Visual Basic da Microsoft SQL Server/Kusrini \& Andri Koniyo. Yogyakarta: ANDI.

Muslim, Rendra. (2014). Pengelolaan Arsip Inaktif Di Dinas Pengelolaan Keuangan Dan Aset Daerah Kabupaten Sleman. Skripsi. Yogyakarta: Fakultas Ekonomi. Jurusan Pendidikan Administrasi, Universitas Negeri Yogyakarta.

Negeri Semarang, Universitas. (2013). Pedoman Arsip Dinamis, (Semarang: Universitas Negeri Semarang).

Nuraida, Ida. (2012). Manajemen Administrasi Perkantoran. Yogyakarta: Kanisius.

Penyusun Kamus Pusat Pembinaan dan Pengembangan dan Pengembangan Bahasa, Tim. (2013). Kamus Besar Bahasa Indonesia. Jakarta: Balai Pustaka.

Penyusun, Tim. (2013). Pedoman Penulisan Skripsi Fakultas Adab dan Humaniora, Palembang: Fakultas Adab dan Humaniora.

Qonitah, Hani. (2013). Manajemen Rekod Aktif, Tanggerang Selatan: Universitas Terbuka.

Rahmawati, N., \& Ismiyati, I. (2016). Pengelolaan Arsip Inaktif Dalam Upaya Mendukung Layanan Informasi Di Kantor Arsip Dan Perpustakaan Daerah Kabupaten Purworejo. Economic Education Analysis Journal, 5(1). Retrieved from https://journal.unnes.ac.id/sju/index.php/eeaj/article/view/10008.

Rosalin, Sovia. (2017). Manajemen Arsip Dinamis. Malang: UB Press. 
Sabera Adib, Helen. (2015). Metodologi Penelitian. Palembang: Noerfikri Offset.

Sujono. (2014). Manajemen Arsip Inaktif. Tanggerang Selatan: Universitas Terbuka.

Sumrahyadi. (2014). Materi Pokok Manajemen Rekod Audio Visual. Tanggerang Selatan: Universitas Terbuka.

Ramanda, R. (2015). Analisis Pengelolaan Arsip Inaktif Terhadap Temu Kembali Arsip Di Pusat Arsip (Record Center) Politeknik Negeri Semarang. Jurnal Ilmu Perpustakaan, 4(3), 211-220. Retrieved from https://ejournal3.undip.ac.id/index.php/jip/article/view/9741.

West, Richard dan H. Turner, Lynn. (2008). Pengantar Teori Komunikasi: Analisis dan Aplikasi, Jakarta: Salemba Humanika. 